\title{
An Energy Stored Quasi Z Source inverter for Photovoltaic Application
}

\author{
K.Dinesh Kumar ${ }^{1}$, D.Arun Prasad ${ }^{2}$ \\ ${ }^{1,2}$ Anna University Chennai, 600 025, India \\ ${ }^{1,2}$ Department of Electrical \& Electronics Engineering, \\ ${ }^{1,2}$ PSNA College of Engineering \& Technology, Dindigul, india- 624622.
}

\begin{abstract}
The quasi-Z-source inverter (qZSI) with battery operation can balance the stochastic fluctuations of photovoltaic (PV) power injected to the grid/load. This work proposes a new topology of the energy-stored qZSI to overcome this disadvantage and delivers the continuous power to the grid/load. The operating characteristic of the proposed solution is analyzed in detail and compared to that of the SPWM and TPWM. Two strategies are proposed with the related design principles to control the new energy-stored qZSI when applied to the PV power system. They can control the inverter output power and manage the battery power, simultaneously. The quasi-Z-source inverter (QZSI) is a single stage power converter derived from the Z-source inverter topology, employing an impedance network which couples the source and the inverter to achieve voltage boost and inversion. The voltage boost and inversion, and energy storage are integrated in a single stage inverter. The validity of the proposed PV system is proved by experimental results, showing an efficient method for the energy-stored $P V$ power generation.
\end{abstract}

Keywords: Energy storage, Photovoltaic(PV) power generation, Power conversion, Quasi-Z-Source Inverter (QZSI), Sinusoidal and Trapezoidal PWM.

\section{INTRODUCTION}

The worldwide-installed photovoltaic (PV) power capacity shows nearly an exponential increase due to decreasing costs and to improvements in solar energy technology. Power converter topologies employed in the PV power generation systems are mainly characterized by two or single stage inverters [1]-[10]. The singlestage inverter is an attractive solution due to its compactness, low cost, and reliability. However, its conventional structure must be oversized to cope with the wide PV voltage variation derived from changes of irradiation and temperature. The two-stage inverter topology applies a boost dc/dc converter to minimize the required kilovolt ampere rating of the inverter and boost the wide-range input voltage to a constant desired output value. However, the switch in the dc/dc converter will increase the cost and decrease the efficiency. The Z-source inverter (ZSI) presents a new single stage structure to achieve the voltage boost/buck character in a single power conversion stage, which has been reported in applications to PV systems [3]. This type of converter can handle the PV dc voltage variations over a wide range without overrating the inverter. As a result, the component count and system cost are reduced, with improved reliability due to the allowed shoot through state. Recently proposed quasi-Z-source inverters (qZSI) have some new attractive advantages more suitable for application in PV systems [3]-[6]. This will make the PV system simpler and will lower cost, because of the following [6]: 1) the qZSI draws a constant current from the PV panel, and thus, there is no need for extra filtering capacitors; 2) the qZSI features a lower component (capacitor) rating; and 3) the qZSI reduces switching ripples seen by the PV panels. In addition, the intermittent and unscheduled characteristics of solar power limit the applicability of PV systems. Therefore, much of the literature suggests the addition of an energy storage system (ESS) to work in conjunction with PV power generation to make its output power continuous, stable, and smooth [5]-[8]. Moreover, when applied as a grid-connected system, it implements other important auxiliary services normally provided by special and expensive equipment (electrical power qualitycontrol, load peak demand control, etc.) [2], [8], [9]. Most of the existing ESS technologies employ a bidirectional dc/dc converter to manage the batteries [5], [6], [8], which makes the system complex, increases its cost, and decreases its reliability.

Pulse Width Modulation is a powerful technique for controlling analog circuits with a power sent to a load. Duty cycle is defined as the ratio of (ton/T), where $\mathrm{T}$ is the period in seconds. There are a several PWM techniques which are being employed for diverse applications, a few of them being sinusoidal, square wave, trapezoidal, stair-case, delta, delta-sigma, space vector, harmonic injection, third harmonic PWM techniques. PWM techniques aim at providing better controllable output voltage along with reduction of harmonics. The project deals with the comparison of harmonic analyses performed by some of the PWM techniques using FFT tool of Simulink in MATLAB, undertaking a few of them, thereby inferring that which technique is the best one among them. 


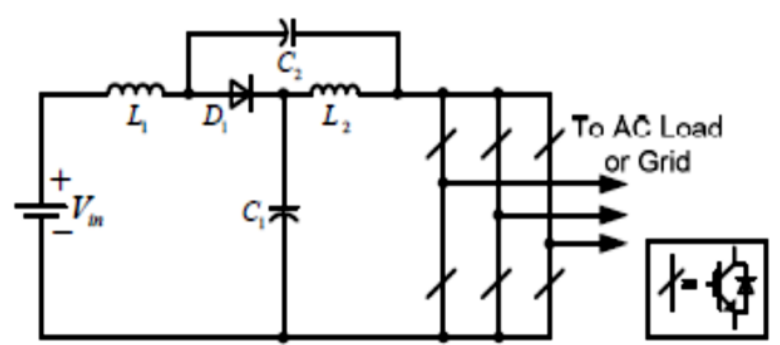

Fig.1. Existing qZSI with battery for PV power generation

Without requirements of any additional dc/dc converters or components, the qZSI was first proposed for PV power generation system. But the solar irradiation and the PV panel's temperature change randomly, the dc-link peak voltage will fluctuate accordingly. So, the additional backup is needed like battery to supply the continuous power to the load. This paper aims to resolve the aforementioned problems, analyze all possible schemes of the energy-stored qZSI, compare their benefits and limitations, and find a new topology more preferable to application in the PV power system.

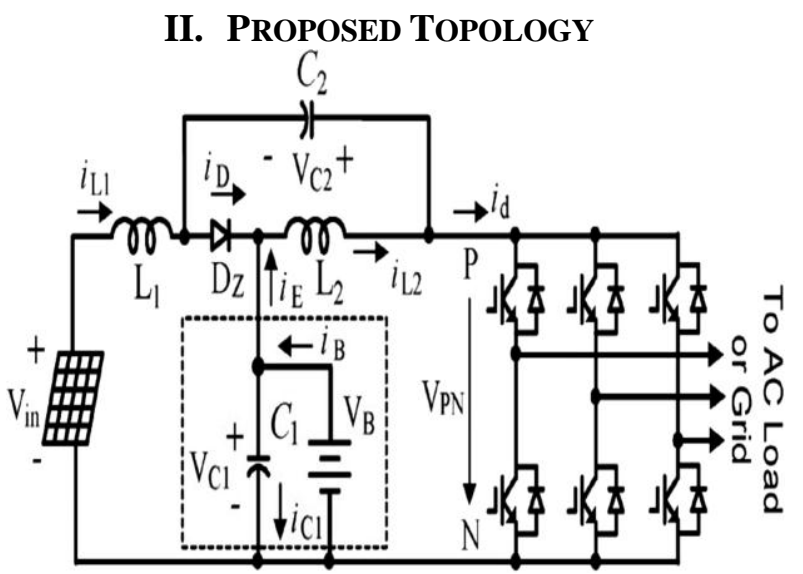

Fig.2. Energy-stored qZSI with battery

Fig. 1 shows just one of the qZSI topologies, if the battery is connected in parallel with the capacitor $C 2$ there is discontinuous mode will occur during battery discharge. As a counterpart, we connect the battery in parallel to the capacitor $C 1$, leading to a new topology in Fig. 2. They have common points: 1) there are three power sources/consumers, i.e., PV panels, battery, and the grid/load, and 2) as long as controlling two power flows, the third one automatically matches the power difference, according to the power equation

$$
\mathrm{P}_{\text {in }}-\mathrm{P}_{\text {out }}+\mathrm{P}_{\mathrm{B}}=0
$$

Where $P$ in, $P$ out and $P B$ are the PV panel power, output power of the inverter and the battery power respectively. The power $P$ in is always positive because the PV panel is single directional power supply, $P B$ is positive when the battery delivers energy and negative when absorbing energy, and Pout is positive when the inverter injects power to the grid.

Modes of operation:

Similar to the existing qZSI operating principle [13], the system in Fig. 2 also has two operating modes in the continuous conduction mode (CCM).

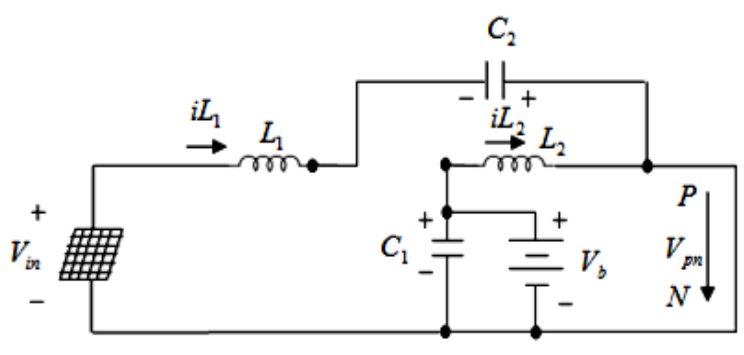

(a) 


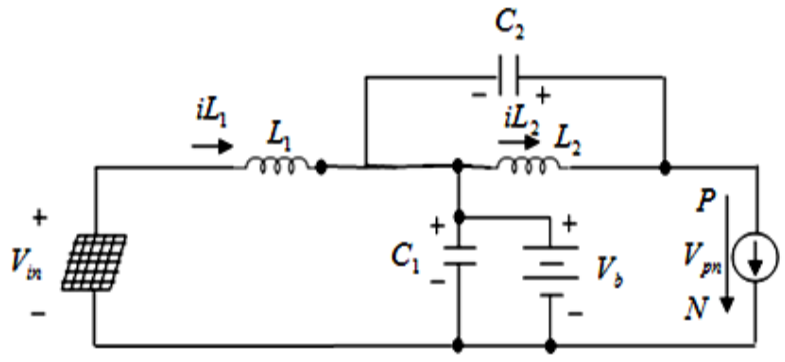

(b)

Fig.3. Two operating modes in theCCM. (a) Shoot through Mode. (b) Non shoot through Mode.

\section{1) Shoot through mode:}

This mode will make the inverter short circuit via any one phase leg, combinations of any two phase legs, and all three phase legs in Fig. 2, which is referred to as the shoot through state [13]. As a result, the diode $D z$ is turned off due to the reverse bias voltage. Its equivalent circuit is shown in Fig. 3(a). During this time interval, the circuit equations are presented as follows:

$$
\begin{aligned}
& \text { C. } \frac{d V_{C 1}}{d t}=i_{B}-i_{L 2} \\
& \text { C. } \frac{d V_{C 2}}{d t}=-i_{L 1} \\
& \text { L. } \frac{d i_{L 1}}{d t}=V_{i n}-V_{C 2} \\
& \text { L. } \frac{d i_{L 2}}{d t}=V_{C 1}
\end{aligned}
$$

Where $\mathrm{i}_{\mathrm{L} 1}, \mathrm{i}_{\mathrm{L} 2}$ and $\mathrm{i}_{\mathrm{B}}$ denote the currents of inductors $L 1$ and $L 2$ and the battery, respectively; $\mathrm{V}_{\mathrm{C} 1}, \mathrm{~V}_{\mathrm{C} 2}$, and $\mathrm{V}_{\text {in }}$ denote the voltages of capacitors $C 1$ and $C 2$ and the PV panel, respectively; $C$ denotes the capacitance of capacitors $C 1$ and $C 2$; and $L$ denotes the inductance of inductors $L 1$ and $L 2$.

\section{2) Non shoot through mode:}

This mode will make the inverter operate in one of the six active states and two traditional zero states, which are referred to as the non-shoot-through state [5]. Continuous current flows through the diode and its equivalent circuit during this time interval, the circuit equations are presented as follows:

$$
\begin{aligned}
& \text { C. } \frac{d V_{C 1}}{d t}=i_{B}-i_{L 1}-i_{d} \\
& \text { C. } d_{C 2}=i_{L 2}-i_{d} \\
& \text { L. } d_{L 1}=V_{i n}-V_{c 1} \\
& \text { L. } \frac{d i_{L 2}}{d t}=-V_{c 1}
\end{aligned}
$$

Where, $i_{d}$ is the load current going to the inverter.

TABLE I COMPARISON OF CURRENT BEHAVIOR FOR TWO INDUCTORS

\begin{tabular}{|c|c|c|c|}
\hline $\begin{array}{c}\text { Input and output power rela- } \\
\text { tion }\end{array}$ & Battery power & \multicolumn{2}{|c|}{ Inductor currents } \\
\cline { 3 - 4 } & & Shoot through mode & Non shoot through mode \\
\hline$P_{\text {in }}<P_{\text {out }}$ & $P_{B}>0$ & $i_{L 2}<i_{L 1}$ & $i_{L 2}>i_{L 1}$ \\
\hline$P_{\text {in }}>P_{\text {out }}$ & $P_{B}<0$ & $i_{L 2}>i_{L 1}$ & $i_{L 2}<i_{L 1}$ \\
\hline$P_{\text {in }}=P_{\text {out }}$ & $P_{B}=0$ & $i_{L 2}=i_{L 1}$ & $i_{L 2}=i_{L 1}$ \\
\hline
\end{tabular}




\section{State Space Analysis}

To study the behavior of any system, modeling and simulation are very essential. State-space analysis is a popular and useful approach for modeling any non-linear and time variant system.

Shoot through mode:

From equations (2) to (5)

$$
\left[\begin{array}{cccc}
C & 0 & 0 & 0 \\
0 & C & 0 & 0 \\
0 & 0 & L & 0 \\
0 & 0 & 0 & L
\end{array}\right] \mathrm{X}=\left[\begin{array}{cccc}
0 & 0 & 0 & -1 \\
0 & 0 & -1 & 0 \\
0 & 1 & 0 & 0 \\
1 & 0 & 0 & 0
\end{array}\right]\left[\begin{array}{l}
V_{C 1} \\
V_{C 2} \\
i_{L 1} \\
i_{L 2}
\end{array}\right]+\left[\begin{array}{l}
i_{B} \\
0 \\
V_{i n} \\
0
\end{array}\right] \mathrm{V}_{1}
$$

Non shoot through mode:

From equations (6) to (9)

$$
\left[\begin{array}{llll}
C & 0 & 0 & 0 \\
0 & C & 0 & 0 \\
0 & L & 0 & 0 \\
0 & 0 & 0 & L
\end{array}\right] \mathbf{X}=\left[\begin{array}{llll}
0 & 0 & 1 & 0 \\
0 & 0 & 0 & 1 \\
-1 & 0 & 0 & 0 \\
0 & -1 & 0 & 0
\end{array}\right] \mathbf{X}+\left[\begin{array}{l}
i_{b}-i_{d} \\
i_{d} \\
V_{\text {in }} \\
0
\end{array}\right] \mathbf{V}_{1}
$$

Inverter system model:

We define $T_{0}$ as the time interval for Mode I and $T_{1}$ as the time interval for Mode II, with a switching cycle $T$. The shoot-through duty ratio is then defined as $\mathrm{d}=T_{0} / T$, and $T=T_{0}+T_{1}$.

Using the state space average method, from (10) and (11), the inverter's state space equation is,

$$
\left[\begin{array}{llll}
C & 0 & 0 & 0 \\
0 & C & 0 & 0 \\
0 & 0 & L & 0 \\
0 & 0 & 0 & L
\end{array}\right] \mathrm{X}=\left[\begin{array}{llll}
0 & 0 & (1-d) & -d \\
0 & 0 & -d & (1-d) \\
(d-1) & d & 0 & 0 \\
d & (d-1) & 0 & 0
\end{array}\right] \mathrm{X}+\left[\begin{array}{l}
i_{B}+i_{d}(d-1) \\
i_{d}(d-1) \\
V_{\text {in }} \\
0
\end{array}\right]
$$

Wherex is the state variables, i.e., $X=\left[V_{c 1}, V_{c 2}, V_{L 1}, V_{L 2}\right]$

At the steady state, the left side of (12) is zero. Therefore, the average voltages and currents have the relationships

From the above equations we get,

$$
\begin{aligned}
& \mathrm{V}_{\mathrm{c} 1}=\frac{1-\mathrm{d}}{1-2 \mathrm{~d}} \mathrm{~V}_{\mathrm{in}} \\
& \mathrm{V}_{\mathrm{c} 2}=\frac{\mathrm{d}}{1-2 \mathrm{~d}} \mathrm{~V}_{\mathrm{in}} \\
& \mathrm{i}_{\mathrm{in}}=\mathrm{i}_{\mathrm{L} 2}-\mathrm{i}_{\mathrm{L} 1} \\
& \mathrm{~V}_{\mathrm{c} 1}=\mathrm{V}_{\mathrm{c} 2}+\mathrm{V}_{\mathrm{in}}
\end{aligned}
$$

The DC line peak Voltage $\quad V_{\mathrm{PN}}=\mathrm{V}_{\mathrm{C} 1}+\mathrm{V}_{\mathrm{C} 2}$

Therefore the DC peak voltage will be,

$$
\mathrm{V}_{\mathrm{PN}}=\frac{1}{1-2 \mathrm{~d}} \mathrm{~V}_{\mathrm{in}}
$$

The voltage $V_{C 1}$ of capacitor $C 1$ will be approximately equal to the battery voltage $V_{B}$ if the voltage drop on the battery's internal resistance is ignored. Thus, from (13), (14), and (16), the dc-link peak voltage $\mathrm{V}_{\mathrm{PN}}$ will be

$$
\mathrm{V}_{\mathrm{PN}}=2 \mathrm{~V}_{\mathrm{B}}-\mathrm{V}_{\mathrm{in}}
$$


Analysis and Comparison:

According to (1) and (13), in Fig. 2, the following can be observed.

1) If $P_{\text {in }}<P_{\text {out }}, P_{B}>0$, and $i_{L 2}>i_{L 1}$, the battery is discharging.

2) If $P_{\text {in }}>P_{\text {out }}, P_{B}<0$, and $i_{L 2}<i_{L 1}$, the battery is charging.

3) If $P_{\text {in }}=P_{\text {out }}, P_{B}=0$, and $i_{L 2}=i_{L 1}$, the battery will not have energy exchange.

Fig. 1 shows significantly different performances because the average currents of its two inductors and battery have the following expression:

$$
\mathrm{i}_{\mathrm{L} 2}-\mathrm{i}_{\mathrm{L} 1}=-\mathrm{i}_{\mathrm{B}}
$$

Table I summarizes both circuits' current behaviors, which presents inverse current relationships for the two inductors when the battery charges and discharges.

In addition, the new topology in Fig. 2 works in the CCM, if

$$
\mathrm{i}_{\mathrm{d}}=\mathrm{i}_{\mathrm{L} 2}+\mathrm{i}_{\mathrm{C} 1}-\mathrm{i}_{\mathrm{B}}>0
$$

During Mode II; otherwise, it works in the DCM if $i_{d} \leq 0$ during Mode II.

In steady state, the average current of capacitor $C 1$ is zero, and (20) will become

$$
\mathrm{i}_{\mathrm{B}}<\mathrm{i}_{\mathrm{L} 2} \text { or } \mathrm{i}_{\mathrm{L} 1}>0
$$

The power equation should satisfy the following inequality:

$$
\mathrm{P}_{\mathrm{B}}<\mathrm{P}_{\text {out }}
$$

It shows that the system represented in Fig. 2 always operates in the CCM during battery charging due to $P_{B}<0, i_{B}<0, i_{L 2}>0$, and $i_{d}>0$. However, the discharging battery is limited by (20) and (22) to ensure that the system in Fig. 2 operates in the CCM. It is noticeable that (22) will be true if (20) is met, but (20) may not be true if (22) is met, because the instantaneous current $\mathrm{i}_{\mathrm{C} 1}$ influences the diode current $i_{D}$ of the $\mathrm{Z}$-source network. The current $i_{D}$ may be decreased to zero during Mode II, which causes the diode to turn off. Thus, the DCM occurs even if the average currents or powers meet (21) or (22).

For Fig. 1, it will work in the CCM, if

$$
\mathrm{i}_{\mathrm{d}}=\mathrm{i}_{\mathrm{L} 2}+\mathrm{i}_{\mathrm{C} 2}-\mathrm{i}_{\mathrm{B}}>0
$$

In steady state, the average current of capacitor $C 2$ is zero, and (23) will become,

$$
\mathrm{i}_{\mathrm{B}}<\mathrm{i}_{\mathrm{L} 1}
$$

The power equation will satisfy the following inequality:

$$
\mathrm{P}_{\mathrm{B}}<\frac{\mathrm{d}}{1-2 \mathrm{~d}} \mathrm{P}_{\text {in }}, \quad \mathrm{P}_{\mathrm{B}}<\frac{\mathrm{d}}{1-\mathrm{d}} \mathrm{P}_{\text {out }}
$$

It shows that the system represented in Fig. 1 always operates in the CCM during battery charging due to $i_{B}<0, i_{L 2}>0$, and $i_{d}>0$. However, the discharging battery is limited by (23) and (25) to ensure that the system in Fig. 1 operates in the CCM. The instantaneous current $i_{C 2}$ influences the diode current $i_{d}$ of the Zsource network. Thus, (25) will be true if (23) is met, but (23) may not be true if (25) is met.

The DCM occurs if the current $i_{d}$ is less than zero during Mode II. From (24), Fig. 4 is drawn to show the battery discharge power ratio over the inverter output power and the limitation of inverter output power for Fig. 1. The battery maximumdischarging power is limited in Fig. 4(a), which causes a limited inverter output power in Fig. 4(b). A DCM occurs if the battery discharging power exceeds its limitation curve, which limits the PV power generation performance of thesystem in Fig. 1.

\section{Sinusoidal And Trapezoidal Pwm}

The sinusoidal PWM technique is very popular for industrial converters. In the SPWM technique, where a triangular carrier wave of frequency fc is compared with the fundamental frequency f sinusoidal modulating wave. The trapezoidal PWM is an advanced technique for inverters and converters. In the TPWM tech- 
nique, where a triangular carrier wave of frequency fc is compared with the trapezoidal modulating wave. The same carrier wave can be used for all three phases.

The following are some major concerns then comparing the two PWM techniques:

i. Low switching losses.

ii. Good utilization of DC power supply that is to deliver a higher output voltage with the same DC supply.

iii. Good linearity in voltage and or current control.

iv. Low harmonics contents in the output voltage and or currents, especially in the low-frequency region.

Boost control of QZSI:

The voltage gain $\mathrm{G}$ of the Z-source inverter can be expressed as,

$$
\begin{aligned}
& G=\frac{V_{\text {out }}}{V_{\text {in }} / 2}=M B \\
& B=\frac{1}{1-2 \mathrm{~d}}
\end{aligned}
$$

Where $\mathrm{B}$ is the boost factor and $\mathrm{M}$ is the modulation index,

$$
M=1-d
$$

Where $\mathrm{d}$ is shoot through duty cycle,

$$
\mathrm{d}=\frac{\mathrm{T}_{0}}{\mathrm{~T}}
$$

Where $V_{\text {out }}$ is the peak value of the output phase voltage, $V_{d c}$ is the input dc voltage, $\mathrm{M}$ is the modulation index, and $\mathrm{B}$ isthe boost factor determined by the shoot-through time interval $\left(T_{0}\right)$ over a switching cycle (T), or the shoot-through duty ratio.

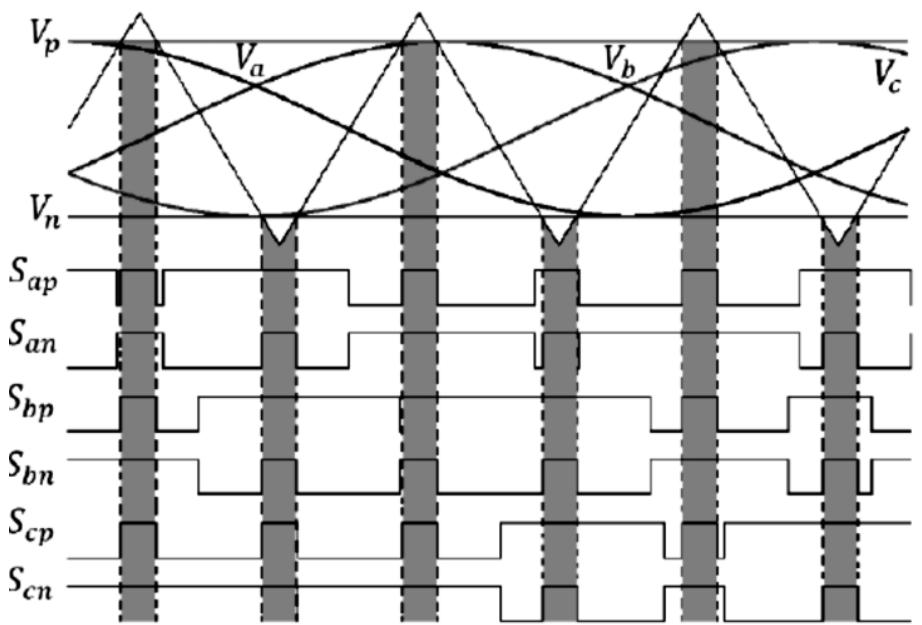

Fig.6. Sketch map of simple boost control

In order to reduce the volume and cost of the Z-source network, we need to eliminate the lowfrequency current ripple by using a constant shoot-through duty ratio. In SBC, there are five modulation curves: two shoot through envelop signal $V p$ and $V n$, and three modulating reference sinusoidal signal $V a, V b$ and $V c$. The amplitude of shoot through envelop signal should be greater than or equal to peak value of modulating sinusoidal reference signal. By comparing dc signal with the high frequency triangular carrier, shoot through switching pulses are generated. The three phase modulating reference signals are compared with high frequency triangular signal to produce the switching pulses. These two signals are compared by a comparator. Therefore when triangular signal is greater than upper envelope $V p$ or less than lower envelope $V n$, the circuit enters into ST state. Because the boost factor is determined by the shoot-though duty cycle, as expressed in (27), the shootthrough duty cycle Fig.5 Sketch map of simple boost control. 


\section{Simulation Study}

The simulation results for the QZSI output voltage, current and FET analysis of SPWM and TPWM is shown in the figure below.
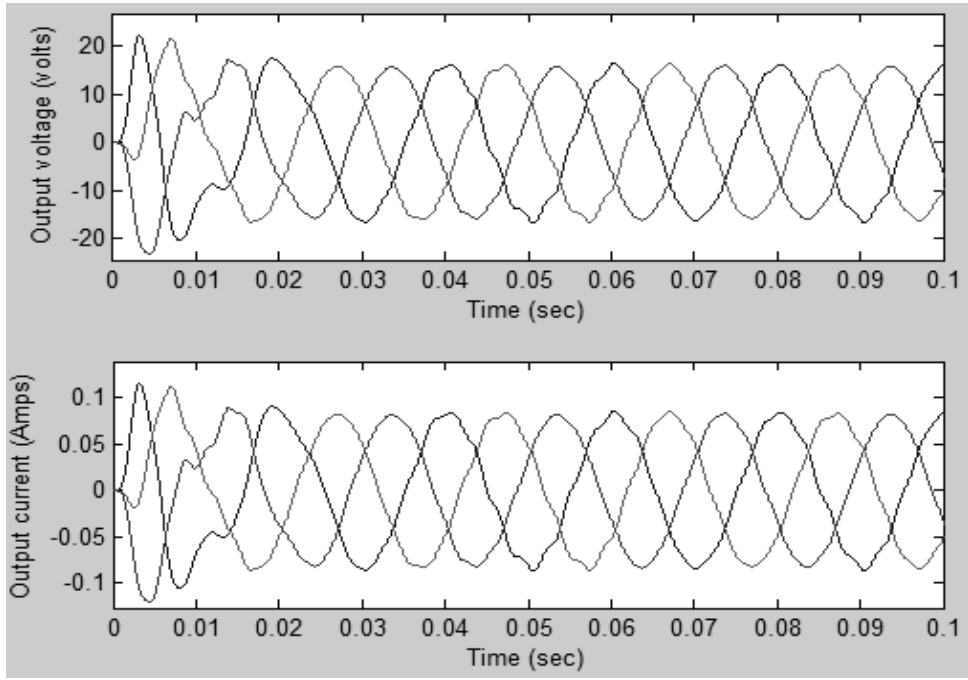

Fig.7. Output voltage and Output current while the system operates in SPWM. Vout=16v, Iout=0.1A with $\operatorname{Vin}=12 \mathrm{v}$ and $\mathrm{d}=0.2$

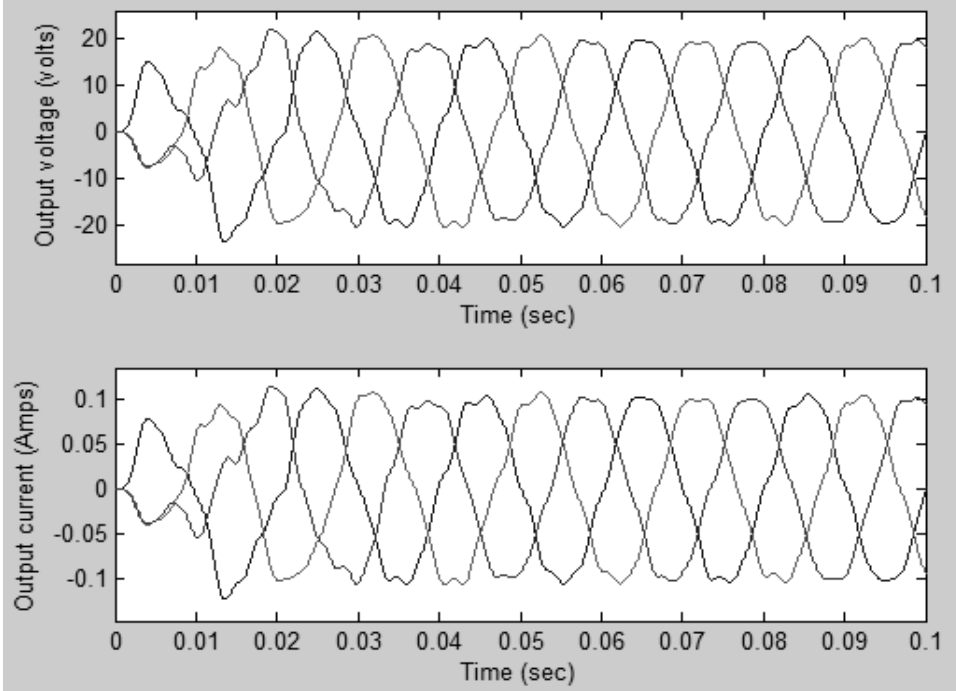

Fig.8. Output voltage and Output current while the system operates in TPWM. Vout=21v, Iout=0.1A with Vin $=12 \mathrm{v}$ and $\mathrm{d}=0.2$

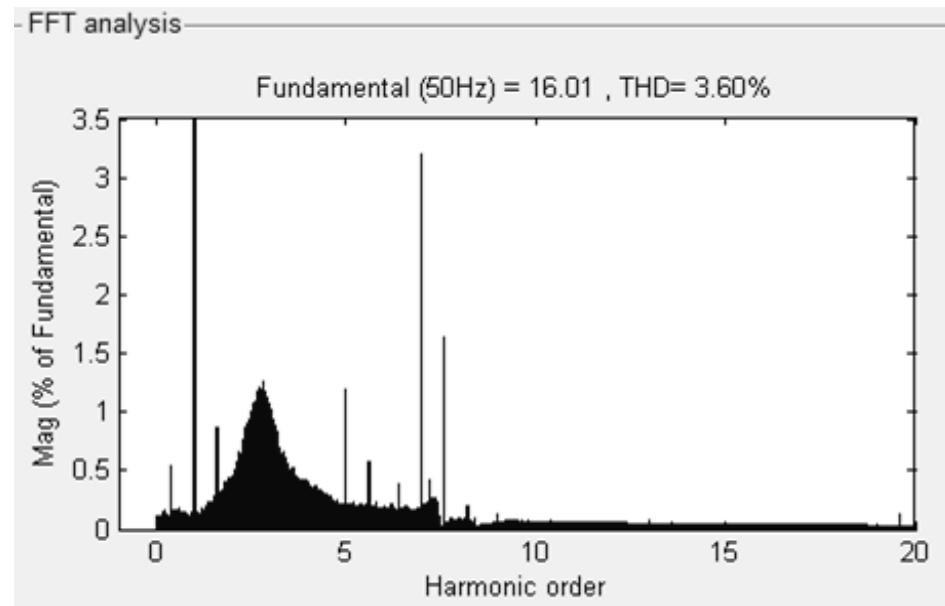

Fig. 9. FET analysis of SPWM(THD=3.60\%) 


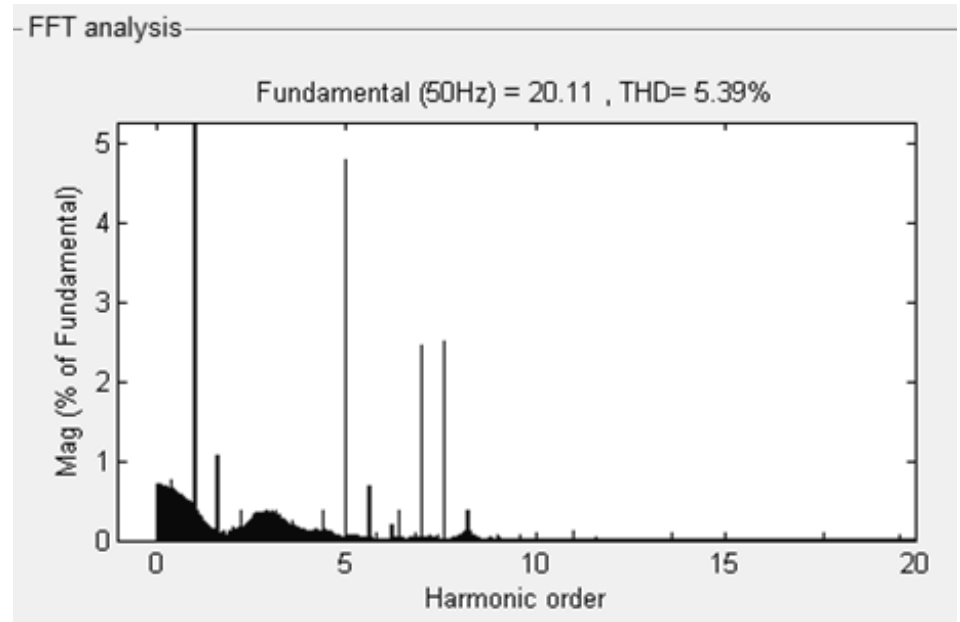

Fig. 10. FET analysis of TPWM (THD=5.39\%)

\section{Conclusion}

In this research work, a novel topology for an energystored qZSI has been proposed to overcome the shortcoming of the existing solutions in PV power system. The theoretical analysis, simulations results presented in this work clearly demonstrate the proposed energy-stored qZSI with sinusoidal and trapezoidal pwm technique. The battery operation can balance the fluctuations from PV panel and supply the continuous power to the grid/load whenever PV panel cannot generate the power due to some low irradiation. There are three power sources/consumers, i.e., PV panels, battery, and the grid/load. As long as controlling two power flows, the third one automatically matches the power difference. So, recently proposed energy stored quasi-Z-source inverters (qZSI) have some new attractive advantages more suitable for application in PV systems. This will make the PV system simpler and will lower cost.

\section{Reference}

[1] J. Chavarria, D. Biel, F. Guinjoan, C. Meza, and J. Negroni, "Energybalance control of PV cascaded multilevel grid-connected inverters for phase-shifted and level-shifted pulse-width modulations," IEEE Trans. Ind. Electron., vol. 60, no. 1, pp. 98-111, Jan. 2013.

[2] D. Vinnikov, I. Roasto, R. Strzelecki, and M. Adamowicz, "Step-up DC/DC converters with cascaded quasi-z-source network," IEEE Trans. Ind. Electron., vol. 59, no. 10, pp. 3727-3736, Oct. 2012.

[3] G. Petrone, G. Spagnuolo, and M. Vitelli, "An analog technique for distributed MPPT PV applications," IEEE Trans. Ind. Electron., vol. 59, no. 12, pp. 4713-4722, Dec. 2012.

[4] D. Vinnikov and I. Roasto, "Quasi-Z-source-based isolated DC/DC converters for distributed power generation," IEEE Trans. Ind. Electron., vol. 58, no. 1, pp. 192-201, Jan. 2011.

[5] D. Vinnikov and I. Roasto, "Quasi-Z-source-based isolated DC/DC converters for distributed power generation," IEEE Trans. Ind. Electron., vol. 58, no. 1, pp. 192-201, Jan. 2011.

[6] ] F. Bradaschia, M. C. Cavalcanti, P. E. P. Ferraz, F. A. S. Neves, E. C. dos Santos, and J. H. G. M. da Silva, "Modulation for threephase transformerless Z-source inverter to reduce leakage currents in photovoltaic systems," IEEE Trans. Ind. Electron., vol. 58, no. 12, pp. 5385-5395, Dec. 2011.

[7] W. Li and X. He, "Review of nonisolated high-step-up DC/DC converters in photovoltaic grid- connected applications," IEEE Trans. Ind. Electron., vol. 58, no. 4, pp. 1239-1250, Apr. 2011.

[8] Q.Tran, T.Chun, J. Ahn, and H.-H. Lee, "Algorithms for controlling both the DC boost and AC output voltage of Z-source inverter,” IEEE Trans.Ind. Electron., vol. 54, no. 5, pp. 2745-2750, Oct. 2007.

[9] C. J. Gajanayake, D. M. Vilathgamuwa, and C. L. Poh, "Development of a comprehensive model and a multiloop controller for Zsource inverter DG systems,"'IEEE Trans. Ind. Electron., vol. 54, no. 4, pp. 2352-2359, Aug. 2007.

[10] M. Shen, J. Wang, A. Joseph, F. Z. Peng, L. M. Tolbert, and D. J. Adams, "Constant boost control of the Z source inverter to minimize current ripple and voltage stress," IEEE Trans. Ind. Appl., vol. 42, no. 3, pp. 770-778, May/Jun. 2006. 